\title{
Self Sovereign Digital Identity on the Blockchain: A Discourse Analysis
}

\author{
http://doi.org/10.21272/fmir.4(2), 65-79.2020.
}

Onat Kibaroğlu, ORCID: https://orcid.org/0000-0002-9743-6251

$\mathrm{PhD}$ Candidate, Faculty of Arts and Social Sciences, National University of Singapore, Singapore

\begin{abstract}
As a technology that can be traced back to the late 1990s in its structural fundamentals, 'blockchain' came into mainstream public discourse as of 2017. Previously discussed in the fringes of the technology-savvy circles, blockchain has now became a global phenomenon and indeed an industry that is rapidly growing and capturing a notable share of the public imagination along with academic discourse. Blockchain's emergence in the realm of technology is essentially thanks to the invention of bitcoin as both a speculative asset and as a digital store of value. Many governments around the world have made public claims regarding their enthusiasm in adopting 'blockchain' in various ways; varying from Russia, Estonia and Ukraine in Europe all the way to Venezuela in Latin America and even the Marshall Islands in the Pacific Ocean. This paper puts out the objective of achieving self-sovereign identities on the blockchain is a promise that has not yet manifested on the ground, albeit it disproportionately captures a significant share of the contemporary discourse on the three larger concepts of self-sovereignty, digital identity and the blockchain. A key reason for the lack of manifestation of this promise is that, there is little agreement as to what is actually meant by 'self-sovereign identities' —in stark comparison to the major consensus over the concepts of 'blockchain' or 'cryptocurrencies'. In order to explore the genealogy of the core concept of 'identity', the theoretical genesis of 'biopolitics' is consulted, demonstrating that our contemporary technological epoch is best defined as an era of the emergence of 'biodigital' power. The paper ultimately argues that the reason for this disproportional share of discourse is created by certain actors to utilise the growing rhetoric on 'blockchain' and the libertarian notion of 'self-sovereignty' as façades to potentially pursue biocapitalist objectives.
\end{abstract}

Keywords: blockchain, self-sovereignty, bitcoin, biocapitalism, digital identity, privacy, data, cryptocurrencies.

JEL Classification: O31; O33; O35; O38.

This work is licensed under a Creative Commons Attribution 4.0 International License.

Cite as: Kibaroğlu, O. (2020). Self Sovereign Digital Identity on the Blockchain: A Discourse Analysis. Financial Markets, Institutions and Risks, 4(2),65-79. http://doi.org/10.21272/fmir.4(2), 65-79.2020.

(C) The Author, 2020. This article is published with open access at Sumy State University.

\section{Introduction: history of blockchain}

As a technology that can be traced back to the late 1990s in its structural fundamentals, 'blockchain' came into mainstream public discourse as of 2017. Previously discussed in the fringes of the technology-savvy circles in the developed regions of the West and Northeast Asia with the appellation of 'distributed ledger technology' (which indeed is a description arguably more illustrative of its actual form of use), blockchain has now became a global phenomenon that is growingly capturing a notable share of the public imagination and academic discourse ${ }^{2}$ in the realm of technology. Within the context of writing of this paper, it can effortlessly noticed in any conference, public seminar and even casual conversation that address any area of technology, the topic of blockchain comes up - and in many occasions, beyond coming up as a mere topic, tends to be the central one.

\footnotetext{
2 "Karl Polanyi wrote in 1944 of a great transformation that drove the logic of markets into social life and created conditions that permitted the rise both of fascisms and social democracies (Polanyi, 1944). We are now in another period of global transformation, in which blockchain technologies are an emerging force (Tapscott \& Tapscott, 2016). Over 80\% of bankers expect to adopt blockchains by the year 2020 (Connolly, 2017). This transition in turn is expected to fundamentally reorder the governance of production, which will have widespread institutional consequences for the global economy (Mac-Donald, Potts, \& Allen, 2016)". - Manski, Sarah. "Building the Blockchain World: Technological Commonwealth or Just More of the Same?" Strategic Change, vol. 26, no. 5, 2017, pp. 511-522., doi:10.1002/jsc.2151.
} 
A key reason for this rather sudden discursive shift in the area of technology (or rather regarding the "next big thing') is the extreme and rapid price increase of 'bitcoin' — an event that spurred the advent of thousands of other digital 'coins' ${ }^{3}$ built on blockchain technology. Bitcoin, in its crudest explanation, is digital cash. It is a digitally created currency and online payment system which is encrypted to enable and regulate the generation ('mining'4), usage (transfer and storage) - all independent of a central bank in any way or form. This particular currency was created by an unknown entity called 'Satoshi Nakamoto' in the late days of 2008 and was released to public during January 2009. The global prominence came about however, between July and December 2017, the price of one bitcoin increased from around USD 2000 to more than USD $19,000^{5}$, as the public interest in it soared proportionately all across the world 6 . The price has been relatively stable around the 10,000 mark ever since, as bitcoin is approaching its 'third halving' by May 2020 at the time of writing?

Through this sudden rise, the expression 'bitcoin' has become (although misleadingly) synonymous with the word 'blockchain' over the past year, carrying each other into the centre of global technology discourse. In a survey during early $2018,60 \%$ of Americans and half of Russian citizens claimed they have heard of bitcoin ${ }^{8}$. Those figures have risen rather rapidly in the next two years, as by mid-2020, $80 \%$ of people in the developed world and $92 \%$ of people in developing countries claim to have heard of cryptocurrencies ${ }^{9}$. Compared to levels of public awareness on other international developments, the ratios could be seen as significant ${ }^{10}$. It is also notable that there is a significantly high usage of cryptocurrencies in emerging markets such as Turkey or Brazil, as opposed to more stable economies such as the UK or France ${ }^{11}$.

Blockchain is a publicly accessible ledger, which in the case of Bitcoin for example, where all the financial transactions that have ever been executed are immutably and publicly stored: “...the [cryptocurrency] blockchain is seen as the main technological innovation of Bitcoin because it stands as a trustless proof mechanism of all the transactions in the network. Users can trust the system of the public ledger stored worldwide on many different decentralised nodes maintained by miner-accountants as opposed to having to establish and maintain trust with the counter-party (another person) or a third party intermediary (a bank)... blockchain allows the disintermediation and decentralisation of all transactions of any type between all parties on a global basis (Swan, 10)"12. As blockchain moved into the central discourse on technology from the fringes of internet forums and relevant clique cypherpunk gatherings, major multilateral and governmental institutions

\footnotetext{
3 “"Cryptocoins, also called cryptocurrency or crypto, are a form of digital currency powered by blockchain technology. Cryptocoins do not have a physical, realworld equivalent. There are no actual coins that represent cryptocurrency value, however, some replicas have been made for promotional purposes or as a visualization tool. Cryptocoins are purely digital" - Stephenson, Brad. "Your Beginners Guide to Bitcoin and Other Cryptcurrency." Lifewire, www.lifewire.com/what-are-cryptocoins-4156406.

4 "Every ten minutes or so mining computers collect a few hundred pending bitcoin transactions (a "block") and turn them into a mathematical puzzle. The first miner to find the solution announces it to others on the network. The other miners then check whether the sender of the funds has the right to spend the money, and whether the solution to the puzzle is correct. If enough of them grant their approval, the block is cryptographically added to the ledger and the miners move on to the next set of transactions (hence the term "blockchain"). The miner who found the solution gets 25 bitcoins as a reward, but only after another 99 blocks have been added to the ledger. All this gives miners an incentive to participate in the system and validate transactions. Forcing miners to solve puzzles in order to add to the ledger provides protection: to double-spend a bitcoin, digital bank-robbers would need to rewrite the blockchain, and to do that they would have to control more than half of the network's puzzle-solving capacity. Such a " $51 \%$ attack" would be prohibitively expensive: bitcoin miners now have 13,000 times more combined number-crunching power than the world's 500 biggest supercomputers". - "How Bitcoin Mining Works." The Economist, The Economist Newspaper, 20 Jan. 2015, www.economist.com/blogs/economist-explains/2015/01/economist-explains-11.

${ }_{6}^{5}$ Appendix A

${ }^{6}$ Appendix B

Barkley, Adrian. "Bloomberg Analyst, Mike McGlone: "Bitcoin's Volatility Has Never Been So Low", May 07, 2020: https://cryptodaily.co.uk/2020/05/bloomberg-mike-btc-low?utm_source=OneSignal\&utm_medium=App

8 "Survey: $60 \%$ of Americans Have Heard of Bitcoin, $5 \%$ Own." Bitcoin News, 24 Jan. 2018, news.bitcoin.com/survey-60-of-americans-have-heard-of-bitcoin5-own/.
}

"Digimentality: FEAR AND FAVOURING OF DIGITAL CURRENCY", May 2020: https://digitalcurrency.economist.com/?utm source=PaidSocial\&utm medium=EIULinkedIn\&utm campaign=CryptoCom

10 "When Newsweek set 1,000 Americans the challenge of completing their country's citizenship test, 29 percent could not name the current vice president (Joe Biden), and almost three quarters could not correctly say why America fought the Cold War. Six per cent could not remember the date of Independence Day. A blind telephone survey of over 1,000 Americans, carried out by the McCormick Tribune Freedom Museum (a museum dedicated to the first amendment), found that more Americans could identify more members of the Simpsons cartoon family than first amendment rights. The first amendment rights guarantee freedom of religion, free speech, free press, association, and the ability to petition government. But only one in a thousand correctly identified all of these. Just one in four Americans could name more than one of their rights, while the same number could name all five members of the Simpson family" - Alsop, Harry. "Americans Surveyed: Misunderstood, Misrepresented or Ignorant?" The Telegraph, Telegraph Media Group, 15 Feb. 2014, www.telegraph.co.uk/news/worldnews/northamerica/usa/10640690/Americans-surveyed-misunderstood-misrepresented-or-ignorant.html.

${ }^{11}$ Appendix C: "Kim Andreasson is the author and Jason Wincuinas is the editor of this report. The analysis is based on a survey of 3,048 people conducted in January and February 2020. About half of the respondents came from developed economies (US, UK, France, South Korea, Australia and Singapore) and half from developing ones (Brazil, Turkey, Vietnam, South Africa and the Philippines).

${ }^{12}$ Swan, Melanie. Blockchain: Blueprint for a New Economy. OReilly Media, Inc., 2015. 
began to catch on and come up with the pioneering use cases of the technology — all of which mostly drawn into the aforementioned 'trustless' nature of the system that promises to get rid of the middleman (formally put, third party intermediary) in any transaction (most typically, the banks).

Almost ironically though, it has been those third party intermediaries who are (theoretically) targeted by the development of this technology, that has shown robust and immediate (considering 2017 as the birth of the mainstream discourse) attention to it. Financial institutions across the board have captured a significant share of the public debate - not only in terms of implementing the infrastructure but also the in terms of directing its thought leadership. Motivated by the prospects of speeding up and simplifying cross-border payments, building smart contracts ${ }^{13}$ and improve their identity data management ${ }^{14}$, they have been vocal in expressing how important the technology will be in the near future: "What if I told you that bitcoin was just the opening act... with the blockchain ready to take center stage" a top official from Goldman Sachs said in a public address during December 2017, claiming that the technology could "change everything"15.

Blockchain has also been on the top of the agenda in the last World Economic Forum in Davos during January $2018^{16}$, while there has been numerous multilaterally organised use cases as well, as in the case of certain United Nations' agencies: “. ...as part of WFP's [World Food Programme] "Building Blocks” project, 10,000 Syrian refugees in Jordan are able to redeem cash-based transfers on a blockchain-based system. The seamless integration of the blockchain into existing technologies allows WFP to use the same process - resulting in no change in the beneficiary experience and disruption to food assistance programs"17.

A similar initiative has also been taken by the Marshall Islands, in order to keep their national legacy alive once, very unfortunately, their lands are submerged under the Pacific in the next decades, due to the climate crisis and the rising sea levels caused by it. ${ }^{18}$ As further but not exhaustive examples of mainstream discussion of the issue in the upper echelons of multilateral institutions, IMF's chief has declared that ".. it would not be wise to dismiss crypto-assets; we must welcome their potential" ${ }^{\prime 19}$ during March 2018, while World Bank officials have recently been coming up with an array of working papers and reports that centre around the topic of blockchain ${ }^{20}$ - all of which illustrate a bright future for the technology underpinned with a positive tone in regards to the opportunities it brings about.

Major governments around the world have also been making various public claims regarding the adoption of the emerging technology ${ }^{21}$. In early 2018, the President of Russia, Vladimir Putin expressed his interest in the subject in an interview: "...colleagues and citizens of the country may ask: Why do we need all this? We

\footnotetext{
13 "Ethereum allows developers to program their own smart contracts, or 'autonomous agents', as the ethereum white paper calls them. The language is 'Turingcomplete', meaning it supports a broader set of computational instructions. Smart contracts can: Function as 'multi-signature' accounts, so that funds are spent only when a required percentage of people agree; Manage agreements between users, say, if one buys insurance from the other; Provide utility to other contracts (similar to how a software library works); Store information about an application, such as domain registration information or membership records" - Palmer, Daniel. "How Do Ethereum Smart Contracts Work?" CoinDesk, CoinDesk, 30 Mar. 2017, www.coindesk.com/information/ethereum-smart-contracts-work/. ${ }_{14}$ Boersma, Jacob, and Blockchain. "5 Blockchain Technology Use Cases in Financial Services | Deloitte." Deloitte Nederland, 21 Mar. 2018, www2.deloitte.com/nl/nl/pages/financial-services/articles/5-blockchain-use-cases-in-financial-services.html.

15 "Deutsche Bank highlighted that the adoption of the blockchain would face "significant legal and regulatory barriers" but recognized that it could be massively disruptive to banks."On one level, this is a wake-up call to the banking industry. Buying and selling across the globe with a cryptocurrency requires no identification, no bank account and no credit card. It pays no foreign exchange fees or banking charges, meaning you could be a bitcoin billionaire without ever having spoken to a bank," the investment bank said. "It could also, of course, be a threat to investments in Uber and Airbnb - and all fintech start-ups that are essentially intermediaries using banking's payment rails." - Kharpal, Arjun. "Why Bitcoin Tech Could Change Everything for Banks." CNBC, CNBC, 31 Dec. 2015, www.cnbc.com/2015/12/31/blockchain-what-the-big-banks-say-about-the-tech.html.

16 “The Future of Blockchain.” World Economic Forum, www.weforum.org/communities/the-future-of-blockchain.

17 "Blockchain allows WFP to virtually eliminate transaction fees paid to third-party financial service providers during the cash transfer process and the project will pay for itself within the first year. Financial risk is also reduced and beneficiary data protection improved. By the end of 2017, WFP aims to scale the project to reach 100,000 Syrian refugees with full roll-out to all Syrian refugees assisted by WFP in Jordan in 2018" - Wayan, Vota. "How Are United Nations Agencies Using Blockchain Technology to Improve International Development Programs?" ICTworks, 26 Feb. 2018, www.ictworks.org/united-nationsagencies-using-blockchain-technology/\#.WtuMZbaB3Us

18 "Climate change means some nations are facing the very real threat of physical destruction — but blockchain-based initiatives may be one way to save the cultural identity of countries like the Marshall Islands... Clearly, there's a very big difference between the words "save" and "preserve." Blockchain technology cannot save the Marshall Islands.But it might help to preserve the Marshallese identity." - Comben, Christina. May 5, 2020. "Extinct or Extant: Can Blockchain Preserve the Heritage of Endangered Populations?": https://magazine.cointelegraph.com/2020/05/05/blockchain-preserve-heritage-marshall-islands/

19 Partington, Richard. "'Fight Fire with Fire': IMF's Lagarde Calls for Bitcoin Crackdown." The Guardian, Guardian News and Media, 13 Mar. 2018 , www.theguardian.com/technology/2018/mar/13/imf-christine-lagarde-calls-bitcoin-crackdown-cryptocurrencies

${ }^{20}$ Natarajan, Harish; Krause, Solvej; Gradstein, Helen. 2017. Distributed Ledger Technology and Blockchain. FinTech Note;No. 1. World Bank, Washington, DC. World Bank. https://openknowledge.worldbank.org/handle/10986/29053

${ }^{21}$ Expectedly, not every aspect of blockchain technologies are immediately welcomed by nation-sate actors, and discussion on this tension is growingly present in academic literature: "Indeed, the Internet and cryptocurrency transactions are by nature borderless, and this sits uncomfortably with traditional regulatory boundaries of jurisdiction and sovereignty. This is particularly so in the case of cybercrime and online misdemeanors: they can originate in one jurisdiction, but have deleterious effects in another, and sometimes on nationals of yet another jurisdiction". — Chuen, David Lee Kuo. Handbook of Digital Currency: Bitcoin, Innovation, Financial Instruments, and Big Data. Academic Press, 2015.
} 
have oil, gas, coals, metals of all kinds... everything! But we need to further advance. This is what we need"22, while the Venezuelan state has launched its own cryptocurrency called 'Petro' ${ }^{23}$ — in (a rather futile) attempt to compensate its financial woes ${ }^{24}$. In Ukraine, the Ministry of Energy has noted in May 2020, that using nuclear power plants for crypto mining could be one of the best ways to take advantage of a current energy glut ${ }^{25}$.

As regards to actual practical uses of the technology however, Estonia stands out. During late 2015, the Estonian government has launched its e-Residency program built on blockchain technology, in which theoretically anyone with access to the internet have the opportunity become a digital citizen of Estonia (albeit with certain security requirements met through background checks). The main purpose of the program is to simplify the process for setting up a business in Estonia, which is a European Union member (hence appealing for many foreign entities to gain a foothold in the trade zone). The Managing Director of the Estonia eResidency program claims that they will also come up with a national cryptocurrency where“...estcoin would be structured to support the objective of growing our new digital nation by incentivising more people around the world to apply for and make greater use of e-Residency"26. Demonstration of such leadership in terms of implementation of blockchain brought a country that is arguably otherwise irrelevant within global affairs, into the centre stage of technology and development debates. Ever since the acclaimed success of its eResidency program has been known to a global audience, the Prime Minister of Estonia has been crisscrossing the world from one conference to another, evangelising the potential of 'blockchain' technology — making him, in a sense, one of the poster-boys of an emerging discourse.

Such cases of public discourse are abundant, all of which indeed illustrating the early days of a potentially ubiquitous technology that is currently widely (and quite understandably given its similar uses cases and structure) hailed as a tool for greater access and democracy for the commons. As Siva Vaidhyanathan reminds though, in a lecture during August 2011, such a discourse was also prevalent during the early days of the internet ${ }^{27}$. The 'information superhighway' (the popular appellation of the internet through the 1990s) promised a more democratised future with ease of access to public debates ${ }^{28}$. Whether or not it has fulfilled that once widely acclaimed promise is a matter of a separate discussion - nevertheless, the trends that the respective technologies spawn (the blockchain and the internet) and the political fringes that they come to amplify is quite compellingly parallel.

In a discourse analysis that critically assesses the very first public debates surrounding bitcoin during 2013 (again, in a similar event to the 'bull market' of 2017, albeit at that time with a much less mainstream appeal beyond the United States), academic David Golumbia draws attention to the ones who wholeheartedly and almost dogmatically promote the technology: “....something far more striking than Bitcoin's explosive rise in value became apparent: in the name of this new technology, extremist ideas were gaining far more traction than they previously had outside of the extremist literature to which they have been largely confined"29 (Golumbia, 1).

\footnotetext{
${ }^{22}$ Bitcoinist. "Vladimir Putin Endorses Blockchain: We Can't Be 'Late In The Race'.” Bitcoinist.com, 25 Feb. 2018, bitcoinist.com/vladimir-putin-endorsesblockchain-russia/.

${ }^{23}$ Al Jazeera. "What Is Venezuela's New Petro Cryptocurrency?” News | Al Jazeera, Al Jazeera, 23 Mar. 2018, www.aljazeera.com/news/2018/02/venezuelapetro-cryptocurrency-180219065112440.html.

24 "The most common category of specific purpose coins was the "national cryptocurrencies," as nations across different continents sought to introduce and accelerate the adoption of their own digital currencies to fulfill their various goals and objectives. These coins, in addition to the usual benefits claimed by altcoins, try to build momentum by appealing to people of certain nationality. Some common themes used include patriotism, sovereignty, nationalism, and even nostalgia" - Chuen, David Lee Kuo. Handbook of Digital Currency: Bitcoin, Innovation, Financial Instruments, and Big Data. Academic Press, 2015.

${ }^{25}$ O'neal, Stephen. "The bureau is now looking to apply progressive solutions to avoid wasting energy as part of the government's course toward digitalization championed by president Volodymyr Zelensky." May 06, 2020: https://cointelegraph.com/news/ukraine-considers-using-nuclear-plants-for-cryptocurrencymining

26 "Estonia E-Residency \& Blockchain Governance, Explained.” CoinCentral, 3 Apr. 2018, coincentral.com/estonia-e-residency-blockchain-governanceexplained/.

27 "The term was first used in 1985 by the 45th US Vice President (1993-2001) Al Gore (born 1948) in an American context where every citizen is aimed to be so connected" - "What Is Information Superhighway? Definition and Meaning." BusinessDictionary.com, www.businessdictionary.com/definition/information-superhighway.html.

${ }^{28}$ uchrivideo. Lecture given at University of Hawaii at Manoa: "SECT VII : Siva Vaidhyanathan - There Is No Such Thing as the Internet." YouTube, YouTube, 8 Feb. 2012, www.youtube.com/watch?v=bKu2MooUTOo.

29 “...Dogma propagated almost exclusively by far-right groups like the Liberty League, the John Birch Society, the militia movement, and the Tea Party, conspiracy theorists like Alex Jones and David Icke, and to a lesser extent rightist outlets like the Fox media group and some right-wing politicians, was now being repeated by many who seemed not to know the origin of the ideas, or the functions of those ideas in contemporary politics. These ideas are not simply heterodox or contrarian: they are pieces of a holistic worldview that has been deliberately developed and promulgated by right-wing ideologues. To anyone aware of the history of right-wing thought in the United States and Europe, they are shockingly familiar: that central banking such as that practiced by the U.S. Federal Reserve is a deliberate plot to "steal value" from the people to whom it actually belongs; that the world monetary system is on the verge of imminent collapse due to central banking policies, especially fractional reserve banking; that "hard" currencies such as gold provide meaningful protection against
} 
As elaborated by Golumbia, growing discourse on blockchain technologies created a robust space and rendered pervasive the phenomenon of 'cyberlibertarianism'. The nature of this phenomena is indeed a subtle one, as "...a set of slogans and beliefs associated with the spread of digital technology incorporate critical parts of a right-wing worldview even as they manifest a surface rhetorical commitment to values that do not immediately appear to come from the [traditional focal points of the political] right" (Golumbia, 2). Cyberlibertarianists30, also often referred to as cypherpunks, therefore, do not have to necessarily come under a well defined roof within the common political spectrum - the phenomenon can be rather defined as a tacitly and loosely associated group of thought leaders, most typically involved in technological undertakings, who boast common objectives and interests - often directed at ending the tyranny of authoritarian governments. In a comprehensive call out to the cypherpunks of the world during May 2020, Luc Dossis claims that "...it seems that the only effective protest is to opt out of the existing system. Voting against the incumbents by exiting the system altogether. And the simplest way to do that is to buy Bitcoin" in his op-ed "Bitcoin as Protest"31.

Some of core and shared values of contemporary (post-2013) cyberlibertarianism is the insistence in net neutrality (which is a popularised term mostly employed by groups who believe governments should not regulate the internet in any way or form), the complete distrust in any state institution (most prominently the central banks and financial regulators) and the almost unquestioned and dogmatic belief that blockchain will promote and ensure total human freedom. The significance of this emerging discourse is that such an anarchocapitalist tone has now pervaded the discourses on 'digital identity' and 'self-sovereignty' as well, legitimised and inspired by the growing global prominence of blockchain. Finding space to operate unreservedly, cyberlibertarian discourse is now at the forefront of debates surrounding both digital identity and selfsovereignty - all debated within the discursive realm of blockchain technologies.

Rendering the issue even more complicated, there is little agreement as to what is actually meant by 'selfsovereign identities' - especially in stark comparison to the major consensus over the concept of 'blockchain'. One industry related individual defines the phrase by claiming that "... self-sovereign identity starts with the notion that we all are the makers of our own identity, online and off. Because they do not rely on any centralized authority, self-sovereign identity systems are decentralized, mirroring the way identity works in real life" 32 , while another elaborates the on the term by explaining that "...self-sovereign identity goes beyond simply providing users with further ownership and control over their cryptographically secure identities, by offering an end-to-end application ecosystem designed to facilitate the commerce and exchange of digital and physical services. It facilitates trust and the secure sharing of information with multiple independent parties across broad networks while preserving traceability and compliance at every end of the transference of data" ${ }^{33}$.

One compelling story demonstrating how a 'self-sovereign identity' is perceived in practical use is the aforementioned story from the Marshall Islands. The small Pacific state is in the development phase of the sovereign (SOV), a digital national currency as of 2020. The cryptocurrency is currently being developed by SFB Technologies, who claim that "...this could be the model for the future of money". The SOV is claimed to be not just another form of currency. Through its blockchain, it provides a way of preserving the Marshallese' financial and political sovereignty beyond the physical limitations of their lands. Anyone transacting and accessing SOV will do so with a digital identity on the blockchain "like a digital passport that allows you to hold and trade" ${ }^{34}$.

\footnotetext{
that purported collapse; that inflation is a plot to steal money from the masses and hand it over to a shadowy cabal of "elites" who operate behind the scenes; and more generally that the governmental and corporate leaders and wealthy individuals we all know are "controlled" by those same "elites." — Golumbia, David. The Politics of Bitcoin: Software as Right-Wing Extremism. University of Minnesota Press, 2016.

30 "Certainly, many leaders in the digital technology industries, and quite a few leaders who do not work for corporations, openly declare their adherence to libertarian or other right-wing ideologies. Just a brief list of these includes figures like Elon Musk, Peter Thiel, Eric Raymond, Jimmy Wales, Eric Schmidt, and Travis Kalanick. Furthermore, the number of leaders who demur from such political points of view is small, and their demurrals are often shallow" - Golumbia, David. The Politics of Bitcoin: Software as Right-Wing Extremism. University of Minnesota Press, 2016.

${ }^{31}$ Dossis, Luc. 06 May 2020: https://medium.com/in-bitcoin-we-trust/bitcoin-as-protest-866a368f55b9?

${ }^{32}$ Quote by Phillip J. Windley is an enterprise architect in the Office of the CIO at Brigham Young University and Chair of the Sovrin Foundation, a non-profit building a global, public network for self-sovereign identity — Windley, Phillip. "How Blockchain Makes Self-Sovereign Identities Possible." Computerworld, Computerworld, 10 Jan. 2018, www.computerworld.com/article/3244128/security/how-blockchain-makes-self-sovereign-identities-possible.html.

${ }^{33}$ Quote by Jed Grant, Founder and CEO of Peer Mountain, a blockchain based technology company — "Self-Sovereign Identities Made Possible with Blockchain.” The Paypers, www.thepaypers.com/interviews/selfsovereign-identities-made-possible-with-blockchain/772096-38.

34 Comben, Christina. May 5, 2020. "Extinct or Extant: Can Blockchain Preserve the Heritage of Endangered Populations?": https://magazine.cointelegraph.com/2020/05/05/blockchain-preserve-heritage-marshall-islands/
} 
Weeding through the technical and rather abstract jargon within such claims, it can be comprehended that self-sovereign identity is being used as a way to express an aspiration towards full autonomy over the usage, storage and transfer one's digital data (be it an individual or corporate entity) — an aspiration in direct relation to what blockchain is promised to bring in contemporary discourse. The rhetoric presented in these excerpts do not explicitly claim 'digital' identities, but for the sake of not complicating and misdirecting their intended message, it can be assumed they are indeed articulating a discussion about digital identities. In order to take a step back and expose the key concepts of digital identity and self-sovereignty, this paper will go through a condensed history of each, with the objective of questioning whether or not 'self-sovereign digital identities' are achievable with the implementation of blockchain technologies.

\section{Literature review: history of digital identity}

In order to explore the genealogy of the core concept of 'identity', the birth of 'biopolitics' can be consulted. Working through a genealogical history in the compilation of his lectures under the name of "Society Must be Defended"35, Michel Foucault introduces the concept of 'biopower', which operates on the site of the individual, through the practice of discipline and mechanical perfection of bodily orientation. The birth of 'biopower' concept is key to generating an understanding of 'identity' and is traced to the earlyindustrialisation era of 17th Century Western Europe - arguably the when the ideological foundations of the modern state are laid. This, according to Foucault represents the initial genealogical shift in the realm of production of knowledge (and in the power relations that are embedded within the society). Foucault then moves on to explain the second genealogical shift (a historical event, in Foucauldian parlance) where "...we see something new emerging in the second half of the 18th Century: a new technology of power, but this time it is not disciplinary... it exists on a different level, on a different scale and because it has a different bearing area, makes use of very different instruments...unlike discipline, which is addressed to bodies, the new nondisciplinary power is applied not to man-as-body but... to man-as-species (Foucault, 242)".

This particular shift is defined by "biopolitics" and its subject is the "population" which it defines through the advent of "statistics" and controls through the processes such as "birth rate, mortality, longevity... a whole series of related economic and political problems (Foucault, 243)". Simply put, "biopower" is to the "individual" while "biopolitics" is to the "population". Modern version of "identity", therefore, can be seen as a concept that is born in the era of 'biopolitics', given its intimate relationship with statistical knowledge production and its positionality within a population.

This concept can be illustrated further with a contemporary perception of identity by Burke and Stets, which approaches the particular term by claiming that identity “... is the ability of the individual to take itself as an object of meaning both from its own perspective as well as from the perspective of others" ${ }^{36}$ (Stets and Burke, 18). This conceptualisation emphasises an inherent duality in any identity, fundamental to its existence. An identity, can be rendered existent only when 'recognised' and 'perceived', hence operates in a relational realm with more than one actor, than a stand-alone concept. That relational realm in this case is a population, where one generates and situates its own and others' identity.

According to another contemporary scholar, Anthony Elliot, within the literature of identity studies, "...identity is something profoundly individual, subjective, personal and private" 37 and "...the cult of identity has become increasingly central to the organization of modern societies" (Elliot, xiv). What is meant by the 'cult of identity' in this case can be read as a celebration (or normalisation) of the idea of absolute difference (uniqueness, originality) between individuals in the post-modern era, as opposed to more general schemes defined by previously prominent forms of identity such as customs (cultures), castes (classes) and religion (and arguably nationalities). Approaching identity from a different angle than situating it in a population, such a definition emphasises the individuality (uniqueness) of an identity rather than its positionality (relational nature $)^{38}$ — albeit not explicitly denying the latter definition.

\footnotetext{
${ }^{35}$ Foucault, Michel, and François Ewald. Society Must Be Defended: Lectures at the Collége De France, 1975-76. Penguin, 2008.

${ }^{36}$ Burke, Peter J., and Jan E. Stets. "Identity Theory.” 2009, doi:10.1093/acprof:oso/9780195388275.001.0001.

${ }^{37}$ Elliott, Anthony. Routledge Handbook of Identity Studies. Routledge, 2017.

${ }^{38}$ This particular approach will be further utilised and situated within the discussion of self sovereign identities on blockchain in the last section of this paper.
} 
Building on these contemporary theoretical definitions and picking up from the genealogical history where Foucault left, it can be claimed that our contemporary era has seen what we can call the emergence of 'biodigital' power. In simple terms, biodigital power stems from the advent and proliferation of the internet, as individuals gain, distribute, manipulate and manage an array of identities within a virtual population which they do not necessarily have to 'fit into'. This shift, therefore, is rooted in pervasive technological advancement and usage, in line with how biopower and biopolitics were generated through different phases of industrialisation and leaps in technological capabilities.

In order to illustrate the contemporary nature of biodigital era, two prolific cartoons that are published during the early of the internet (July 1993) ${ }^{39}$ and more recently (April, 2015) ${ }^{40}$ on the globally influential New Yorker magazine can be discerned. The first cartoon, now famously known as the "On the Internet, nobody knows you're a dog" has become almost a proverb in the conversations about Internet anonymity. This particular illustration features two dogs where one is sitting on a chair in using a desktop personal computer, with the caption directed towards a second dog sitting on the floor listening to the him. The second cartoon is a belated follow up, where the seat is taken by a human being while one dog to another claims "Remember when, on the internet, nobody knew who you were?". What is significant about the messages embedded in these illustration is that the brief yet charged story they employ cannot be discerned with the conceptual tools of biopower and biopolitics - making a new concept such as 'biodigital' necessary to understand their essence and context. The two cartoons can be said to encapsulate how the biodigital era is defined by the tension between an aspiration and conviction of full anonymity 'on the internet' versus an acceptance of not achieving that level of control over the past decade ${ }^{41}$ - a debate that is central to current discourses on digital identity, privacy and autonomy.

Without further ado, it must be be readily acknowledged that this exploration of the concept of identity is one that is centrally concerned with the digital version of it - one that is geared towards deepening the understanding of 'identity' within the technology-oriented discourse of 'self-sovereign identities on blockchain" ${ }^{42}$. It is by no means an attempt at presenting a comprehensive history of the larger and colossal discourse on identity, but rather a niche and pragmatic approach that is majorly concerned with fleshing out the term 'identity' before haphazardly using it in technology related discussions. Moving on, with a similar approach and objective, the paper will expose certain scholarly literature around the concept of selfsovereignty, in order to situate the expression in a larger discursive context than its current prominent use within blockchain related debates.

\section{Methodology}

Conventionally observed in debates within the disciplines of political science, sociology, anthropology and philosophy, the concept of 'self-sovereignty' has recently entered technology related discourses, driven majorly by the advent of blockchain. Scholarly literature on this concept has not yet caught up to the growing discourse on 'achieving self-sovereign identities through blockchain technology, ${ }^{43}$, but the topic is prominently featured in global media outlets along with governmental and multilateral policy making circles. A key aim of this paper then, is to bring a discussion that must be (but currently is not) taking place in an academic context, due to its inherent multidisciplinary nature and complexities, into that particular realm of debate. This 'history of self-sovereignty', thus can be read as an experimental discourse analysis that discerns the contemporary usage of the concept.

A prominent example of this discourse displayed in the policy making circles is the much publicised efforts of the Estonian government in regards to "spreading sovereign jurisdiction on the blockchain". In December 2015, the Estonian government started offering a blockchain based public notary scheme to its e-residents (be

\footnotetext{
${ }^{39}$ Appendix D

${ }^{40}$ Appendix E

${ }^{41}$ For contexualisation of these discourses, see Appendix F. As a prominent event ongoing through 2018, Facebook is in the centre of the contemporary discourse surrounding personal privacy and digital data control.

${ }^{42}$ An alternative genealogy or more so a categorisation of digital identity is common in blockchain related discourses that move through relatively highly technical concepts of the internet infrastructure that is not as relevant to the discussion of the 'biodigital' era as much as the genealogy presented in this section. ${ }^{43}$ There has been discussion of relationship of sovereignty and blockchain (not particularly self-sovereignty) in regards to corporate entities, not individual identities that constitute the focus of this paper: "blockchain technologies are already being used in ways that tend against the kind of democratic governance and ownership essential to the construction of a technological commonwealth. Specifically, some blockchain applications tend toward the widening of the technological divide, an increase in automation and stratification, new forms of deregulation, and the emergence of corporate sovereignty". - Manski, Sarah. "Building the Blockchain World: Technological Commonwealth or Just More of the Same?" Strategic Change, vol. 26, no. 5, 2017, pp. 511-522., doi: $10.1002 /$ jsc. 2151 .
} 
it Estonian nationals or not), enabling the notarisation of their marriages, birth certificates, land titles, and business contracts on the blockchain. The officials involved in the project declare that this development enables people to have self-sovereignty (used at times synonymously with self-ownership in various outlets) over their identities ${ }^{44}$. Such a claim is based on the conviction that citizens that are covered with this scheme can now choose how and when their personal data is going to be used. It is significant to note that this particular project in Estonia has been crafted and employed through a partnership with a private entity called "Bitnation", which is a widely acclaimed blockchain service provider ${ }^{45}$ that enables so called 'DIY ${ }^{46}$ governance'.

Contemporarily, market demand for such services is growing across the board. As another example regarding the use of blockchain for digital identity creation, two major multinational corporate entities, Microsoft and Accenture, have partnered to come up with a tool that creates digital identities for refugees ${ }^{47}$. In regards to the current developments in the financial sector, the emergence of Lenddo, a Southeast Asian credit-scoring startup, is an illustration. Targeting the inconveniences in regards to corporate banks' requests for loan provision, (which include verified identification documents, employment letters, utility bills and multiple guarantors, all of which resources that are lacked by a vast number of the population in Southeast Asia) Lenddo has developed a software platform that analyses a huge number of data points, ranging from a smartphone user's messaging and browsing activity, battery usage and the Wi-Fi networks they use ${ }^{48}$. Lenddo is only one of many startups that employ similar practices and offerings in the larger universe of blockchain technologies. Despite the overwhelmingly positive publicity they receive and their promise of bringing greater convenience to 'untapped' regions and populations, such practices (such as e-residencies, digital identity provision and eased credit scoring on the blockchain), especially when pursued by private entities, can be seen potentially linked to a pursuit of 'biocapitalism'.

\section{Discussion: biocapitalist objectives of blockchain projects}

Considering the genealogy of the concept of 'biodigital' to be central to the approach to 'digital identity', an exploration of the concept of 'biocapitalism' will set the framework of the approach to 'self-sovereignty'. Thus, assessing the concept through this lens, the recent book 'Fungible Life' that published in 2016 on the Singaporean Biopolis research centre, by Aihwa Ong will be revisited. The literature presented in the book discuss 'biocapitalism' in Asia ${ }^{49}$, riding on the definition that it is an exploitative pursuit of bodies (flesh and labour in different instances), driven by the motivation "... of making more of life that goes beyond enhancing the vital future individual consumers" ${ }^{50}$ (Ong, 12). The key tool that generates and expands the pursuit of

44 Allison, I. Bitnation and Estonian government start spreading sovereign jurisdiction on the blockchain. IBTimes, February 8 2016. http://www.ibtimes.co.uk/bitnation-estonian-government-startspreading-sovereign-jurisdiction-blockchain-1530923

${ }^{45}$ Bitnation introduces itself as the "...the world's first Decentralised Borderless Voluntary Nation (DBVN). Bitnation started in July 2014 and hosted the world's first blockchain marriage, birth certificate, refugee emergency ID, World Citizenship, DBVN Constitution and more. The website proof-of-concept, including the blockchain ID and Public Notary, is used by tens of thousands of Bitnation Citizens and Embassies around the world. Bitnation is the winner of UNESCO's Netexplo Award 2017, and has been featured by the Wall Street Journal, Bloomberg, BBC, CNN, WIRED, VICE, TechCrunch, The Economist, Russia Today among many others" on its corporate website: https://tse.bitnation.co

${ }^{46}$ Shorthand expression for 'do it yourself', implying self-determination of a practice.

47 “.... a new software tool, unveiled on Monday at the United Nations, is a big deal. It will let millions of refugees and other without documents whip out a phone or other device to quickly show who they are and where they came from. The tool, developed in part by Microsoft and Accenture, combines biometric data (like a fingerprint or an iris scan) and a new form of record-keeping technology, known as the blockchain, to create a permanent identity. In practice, this means someone arriving at a border crossing could prove he or she had come from a refugee camp and qualify for aid. Or a displaced person in a new country could use the ID system to call up his or her school records. The tool doesn't have a name yet since it's at the prototype stage but will get one soon" — "Refugees Can Prove They Are With This New Technology." Fortune, fortune.com/2017/06/19/id2020-blockchain-microsoft/.

48 “Alternative Credit Scoring Providers In Southeast Asia You Have To Know." Fintech Singapore, 10 June 2017, fintechnews.sg/9695/bigdata/alternativecredit-scoring-providers-southeast-asia-know/.

${ }^{49}$ There is a rich selection of literature of Foucauldian approach to bioscience in Asia. An example is Stefan Ecks' anthropological work in India that explores the concept of self-care within a realm of biopolitics and medicine: "Popular health writings of the colonial era envisioned that if individual sovereignty over one's own body can be achieved, collective sovereignty in the sphere of culture and politics is near. In Kolkata today, this critique of colonial dependency is transformed into a critique of 'modern' modes of dependency. Yet between the lines, the criticisms of defective modernization retain a utopian vision of the future. One day, we will not just become modern subjects, but sovereigns of modernity. One day, we will hold health in our own hands again. One day, modernity will be digested. It is this link between utopian thought and technologies of self-care that Foucault's works on ethics help to understand. Looking beyond this example from contemporary Kolkata, a Foucauldian attention to self-care promises to shed new light on many more issues in medical anthropology. Anthropologists working in India have not yet carried out any systematic study on how people reflect on the consequences of modernity, and how bodily technologies of self-care might be interpreted as strategies to counter the unwanted side-effects of modernization. A number of serious questions about the possible limitations of Foucault's theory remain. To name but one, a certain bias towards masculine modes of self-subjectivization awaits further discussion. However, given that Foucault's early works on power have so deeply influenced anthropological understandings of colonial and postcolonial health care practices, it can be imagined that Foucault's work on self-care might soon be seen as equally compelling”. — Ecks, Stefan. Bodily sovereignty as political sovereignty: 'self-care' in Kolkata, India, Anthropology \& Medicine, 2004 11:1, 75-89, DOI: 10.1080/1364847042000204906

${ }^{50}$ Ong, Aihwa. Fungible Life: Experiment in the Asian City of Life. Duke University Press, 2016. 
'biocapital ${ }^{51}$ in this case, is elaborated as genomic sciences, which she argues, operate within an interplay of biology, politics, the environment and market forces - a nexus that that is "...experimenting with different visions of the future" $(\mathrm{Ong}, 5)^{52}$. As an example of a negotiation of power within this nexus is Indonesia's refusal of giving out its citizens H5N1 viral specimens (biocapital) to the World Health Organisation (WHO) in 2008. Such exercise of 'self-sovereignty' resulted in large pharmaceutical corporations affiliated with (lobbying through) the WHO to offer their vaccinations at much more affordable prices in order to obtain the particular data, illustrating a mediation of interests between scientifically, politically and financially oriented actors that make up the biocapitalistic sphere altogether ${ }^{53}$.

Building onto the framework set by the discussion of biocapitalism and in order to flesh out the aforementioned expression of the of 'self-sovereignty', it is also critical to discern the underlying fundamental concept of 'consent'. Given that any attempt at understanding self-sovereignty, can be seen as essentially a discussion stemming from the negotiation of consent - a topic all the more relevant to public discourse with the emergence of the COVID-19 pandemic during 2020 and the measures taken to tackle it.

In her work "Informed consent, body property, and self-sovereignty" 54 that is published in 2016, Radhika Rao formulates certain questions that address the core facets of 'biocapitalism' (although without mentioning the particular term): "What counts as informed consent?... What property rights does the donor own [in regards to his or her] biological specimen?... Does the donor have a right to share in the resulting profits?" (Rao, 437). To translate these inquiries back to the context that this paper is particularly concerned, the expression 'donor' can be read as 'user' and 'specimen' as 'data' - feeding into the notion of living in a biodigital era, where our bodies (hence its specimens) are generated and represented as an accumulation and arrangement ${ }^{55}$ of digital data. In an attempt to respond to such questions, Rao turns to classifying consent into three versions. Acknowledging the importance of genuine practice of informed consent, Rao claims that a version of consent is merely the absence of coercion, where the subject accepts to provide a specimen (read: a user that provides data) simply does so after meeting bureaucratic formalities (such as ticking boxes in a 'consent form' or accepting a rather enigmatic and charged-laden 'terms and conditions' agreement). The second form of consent is the failure (or unawareness of the ability) to opt-out. Such an approach, and indeed exploitation of consent is widespread in most occasions that involve signing up for any sort of social media account (hence creating a new digital 'identity'). The third version of consent that is discussed in the paper is 'actual affirmative consent', that envisions a rather impractical (and hypothetically, according to any subject, most desirable) version of consent where the subject is fully aware of the implications of its decision and can negotiate where and how its data can be used. This particular version of consent can be interpreted as the vital and unassailable component of a vision of self-sovereignty. What renders such a vision impractical and so far only abstract is that it results in an overload of information within an array of infinite (and utopian) offering of choice - potentially overwhelming any individual or system to set the options of decision that consent will be practiced upon. Therefore, “....informed consent inevitably requires a choice between whether to provide too little or too much information" in practice.

\footnotetext{
${ }^{51}$ Enlarging the approach to biocapital, it can be also imagined with the simplistic comprehension Thoreau introduces: “...the cost of a thing is the amount of life which is required to be exchanged for it, immediately or in the long run". — Trotter, Griffith. Autonomy as Self-Sovereignty. HEC Forum (2014) $26: 237$. https://doi-org.libproxy1.nus.edu.sg/10.1007/s10730-014-9248-2

${ }_{52}$ As a critical response to the wide array of bio-concepts that scientists with the similar approach of Ong introduce to the discourse, Birch and Tyfield claim that: "Several STS [science and technology studies] scholars in the past decade or so have theorized the articulation of capitalism and biotechnology. Out of this meeting have come a number of theories positing particular political-economic relationships including biovalue (Waldby 2000), bioeconomics (Rose 2001), biocapital (Rajan 2006), and life as surplus (Cooper 2008). There are a number of other accounts of this articulation worthy of a full review in their own right (e.g., "genetic capital," "'organic capitalism," "biowealth," etc.); something that is beyond the scope of this article. However, Stefan Helmreich (2008) has written an enlightening review of the evolution of these various concepts, which does much of the work for us. He identifies two particular clusters of theories or "species of biocapital": first, a Marxist-feminist cluster concerned with production and reproduction; and second, a Weberian-Marxist cluster concerned with how "relations of production are described alongside accountings of ethical subjectivity" (Helmreich 2008, 471). This latter cluster is also heavily influenced by the Foucauldian concept of biopolitics. In this article, we focus on this latter, largely Foucauldian perspective. It is clear that scholars from both "species", are engaged in a serious attempt to rework Marxist categories, which we do not want to denigrate. However, we would suggest that some of these reworkings are less productive than others, especially in their adoption of political-economic categories and terminology. This is particularly clear once we take seriously the foundation of a Marxian political economy, namely the LTV (or value theory of labor per Elson 1979)". - Birch, Kean, and David Tyfield. "Theorizing the Bioeconomy: Biovalue, Biocapital, Bioeconomics or . . . What?” Science, Technology, \& Human Values, vol. 38, no. 3, Nov. 2012, pp. 299-327., doi:10.1177/0162243912442398.

${ }^{53}$ Ong, Aihwa. Fungible Life: Experiment in the Asian City of Life. Duke University Press, 2016.

54 Rao, Radhika. "Informed consent, body property, and self-sovereignty." Journal of Law, Medicine \& Ethics, Fall 2016, p. 437+. LegalTrac, http://link.galegroup.com/apps/doc/A466051977/LT?u=nuslib\&sid=LT\&xid=a2909bca

${ }^{55}$ In its crudest version, just like the way the human body can be considered as 'food rearranged', our digital identities are in a sense 'bytes rearranged'.
} 
Self-sovereignty is therefore inherently built upon informed consent and thus a perfectionist objective that requires a rather overwhelming variety of choices. An individual navigates within this untethered ocean of possibilities utilising his or her autonomy, which can be conceived as a certain prerogative of personal choice are granted to him or her, directed towards a variation or inventory of permissible decisions ${ }^{56}$. It is clear then, whichever understanding of consent and autonomy is taken up to build an understanding of self-sovereignty, such an understanding is bound to be critically assessed in regards to the assumption of an individual's competence and possibility to direct its own decisions from a set of choices ${ }^{57}$.

\section{Results: the saga of self sovereign digital identity on the blockchain}

Ultimately, this paper aimed to dissect and poke at concepts embedded into the contemporary discourse of 'self sovereign digital identities on blockchain', working through a brief discourse analysis surrounding each word, in reverse order. The histories that have been presented focus on the relevant aspects of these rather colossal discourses (blockchain, digital identity and self-sovereignty), to build an informed understanding of the recently burgeoning discourse of achieving self sovereign digital identities through the implementation of blockchain technologies. As a template to closely analyse the contemporary discourse on 'self sovereign digital identities on blockchain', a widely cited article that extensively sets out the key building blocks of this objective will be addressed. In a public proposal, named "The Path to Self-Sovereign Identity" published in 2016, Christopher Allen claims that in order for a digital identity to be considered self-sovereign, it "...must balance transparency, fairness, and support of the commons with protection for the individual" 58 and should meet the following ten principles of usage: control, access, existence, transparency, persistence, portability, interoperability, consent, minimalisation and protection. Building on the genealogies discussed till this point in this paper, arguably the five major principles among the list, 'control', 'access', 'existence', 'transparency' and 'consent', will be explored in search of both their theoretical reasoning and potential practicality.

In regards to the principles of 'control' and 'access', the earlier presented cartoons from the New Yorker ${ }^{59}$ can be deemed illustrative. The messages embedded in each of the cartoons demonstrate a shift of discourse from a widespread belief in full anonymity 'on the internet' to this time a widespread acceptance of the lack of privacy it brought about. Such a shift of discourse can be hypothesised to be observed in the near future once again, in regards to the parallel contemporary conviction that anonymity and full control over one's digital identity can be achieved 'on the blockchain'. Drawing lessons from the trajectory of the discourse surrounding digital identities on the internet, it can be inferred that once the practical use cases of aforementioned 'selfsovereign identities' will become more widely used, the pitfalls of such convictions will be exposed — as it was with the past decade of mainstream usage of the internet ${ }^{60}$. Total control (or even full awareness) of one's digital identity data, be it a truthful one or not, is now rendered rather impossible, given amount of exposure a digital identity gets in a daily usage of internet platforms - a phenomenon that is simplified as the 'digital footprint ${ }^{\prime 61}$. Blockchain is thus presented as a cure to this loss of control, claiming that it will make any entity,

\footnotetext{
56 Trotter, Griffith. Autonomy as Self-Sovereignty. HEC Forum (2014) 26: 237. https://doi-org.libproxy1.nus.edu.sg/10.1007/s10730-014-9248-2

${ }^{57}$ Self-sovereignty is also a part of a political discourse that revolves around the conceptualisation of ownership and rights, a discourse which operates mostly out of the framework of 'biocapital' that is central to this paper: " there are two important dialectical points I shall make. The first is that I take the principle of self-ownership to employ an ineliminable conception of property rights: It says that I enjoy the very same set of rights over myself and my powers as I enjoy over my privately owned bicycle and its powers. This puts me at odds with some of the principle's most ardent recent defenders. Thus, for instance, Michael Otsuka allows that "talk of property in persons might strike some modern ears as an artificial and unwarranted extension of the concept of property." But he then invites people of this persuasion to "mentally delete the words 'property' or 'ownership' ... and replace them with an assertion of the relevant rights." 15 Otsuka here is advocating an eliminativist conception of ownership: Ownership, for him, is simply a matter of possessing certain rights and these rights are not, at bottom, property rights at all. It is this I reject. I take it that to predicate the moral relation of ownership between a human being and some item is to postulate a rock bottom sui generis normative relationship between her and that thing". - Hinton, Timothy. "Equality, Self-Ownership, and Individual Sovereignty." The Philosophical Forum, vol. 44, no. 2, 2013, pp. 165-178., doi:10.1111/phil.12009.

${ }_{58}$ Allen, Christopher. "The Path to Self-Sovereign Identity." CoinDesk, 1 May 2016, www.coindesk.com/path-self-sovereign-identity/.

${ }^{59}$ Appendices $\mathrm{C}$ and D

60 " If a person uses an identity provider such as Facebook Connect, the person delegates all management to that service. This includes the responsibility to protect their privacy and to ensure the trustworthiness of their data. However, the person typically has little insight into the actual handling of his digital identities. At the same time, the person has to make only few decisions, as eg. about the technology for the secure storage or transmission of data. The person thus exchanges some of his control over his digital identities for a certain comfort". - Janichen, Stefan, et al. "Self-Sovereign Identity - Opportunities and Challenges for the Digital Revolution." FZI Forschungszentrum Informatik Am Karlsruher Institut Für Technologie, Karlsruhe., 2017, arxiv.org/pdf/1712.01767.pdf.

61 "The potential for mischief with digital footprints was signalled by many commentators, including a March 2013 report by Cambridge University's Psychometrics Centre in collaboration with Microsoft Research. The report concluded: that "digital records of behaviour, Facebook Likes, can be used to automatically and accurately predict a range of highly sensitive personal attributes including: sexual orientation, ethnicity, religious and political views, personality traits, intelligence, happiness, use of addictive substances, parental separation, age, and gender... Big Data and AI can deliver intended and unintended consequences. They can bring convenience or invade privacy — both to an unprecedented extent. Amazon selects personalized products;
} 
be it a corporate, government or individual, impossible to control or access biodigital identities. It is proposed that this would be achieved through a "...mathematical policy, where cryptography is used to protect a user's autonomy and control" and also by addressing "....self-sovereign identity as a legal policy; [defining] contractual rules and principles that members of their network agree to follow". At this point, such aspirations can be responded to by borrowing some wisdom from David Golumbia's work, which reminds us that it is a "...delusional hope that a protocol, a procedure, a network, an algorithm can neutralise the selfish traits of human beings" (Golumbia, 21) ${ }^{62}$.

Moving on to the principle of 'existence', it is claimed in a separate journal article published in 2017 that "... self-sovereign identity not only gives individuals the highest level of control over its data, but selective sharing of personal data with service providers follows the idea of data economy and privacy by default/design" ${ }^{\circ 3}$ (Janichen, et al., 3). As much as such an aspiration is feasible in very simple forms of offline interaction (owning a residence permit and presenting it in necessary contexts), human identities and their ever-changing biodigital features are in practice too complex, widely spread and varied to be captured in a single system. Even if such a technological depiction is made, for example with the usage of blockchain based e-residencies or e-passports in Estonia, it is misleading to imagine that one's biodigital identity is exclusive to that particular platform or system. Therefore, what is technologically achievable is the creation of the digital version of a conventionally offline 'identity' (a residency permit) - but not a 'self-sovereign biodigital identity'. In regards to the proposed principle of 'transparency', it is important to note that shifting the authorisation of the truthfulness of an identity into a blockchain system simply "...shifts the problem of trustworthiness: instead of proving the authenticity of the information, the person must prove the authenticity of the evidence" $" 64$ (Janichen, et al., 2). Any blockchain, therefore does not necessarily dispel the need for trusted authorities in transactions, as current prominent literature on it claims ${ }^{65}$, it actually distributes this authority to decentralised nodes (as opposed to a central authority like the state or a bank). Cyberlibertarian rhetoric $^{66}$ that supports such a power shift, as elaborated earlier, almost dogmatically pursue the notion that this is the correct sort of disruption, echoing an anarchic disposition towards formal institutions. How and why the recently emerging blockchain companies that propose to handle and verify such data must be trusted more than formal institutions is a reasoning that is commonly lacking.

The objective of achieving self-sovereign identities on the blockchain is therefore a promise that has not yet manifested on the ground (nor can be expected to), albeit it disproportionately captures a significant share of the contemporary discourse on the three larger concepts of self-sovereignty, digital identity and the blockchain. As informed from the discussions throughout this paper, it can be hypothesised, the reason for this disproportional share of discourse might be created by certain actors to utilise the growing rhetoric on 'blockchain' and the libertarian notion of 'self-sovereignty' as façades to potentially pursue biocapitalist objectives.

\section{References}

1. Altshuler, Yaniv (2014). Security and Privacy in Social Networks. Springer. Available at: https://www.springer.com/gp/book/9781461441380.

2. Amrute, Sareeta (2016). Encoding Race, Encoding Class: Indian IT Workers in Berlin. Duke University Press. Available at: https://read.dukeupress.edu/books/book/62/Encoding-Race-Encoding-ClassIndian-ITWorkers-in

3. Birch, Kean, and David Tyfield (2012). Theorizing the Bioeconomy: Biovalue, Biocapital, Bioeconomics or . .. What? Science, Technology, \& Human Values, 38(3), 299-327. DOI: 10.1177/0162243912442398.

4. Burke, Peter J., and Jan E. Stets (2009). Identity Theory. DOI: 10.1093/acprof:oso/9780195388275.001.0001.

Twitter, Facebook and Instagram, the most appealing posts; Apple and Netflix, music and videos — all on the basis of internet footprints. But data and tools in the wrong hands, or insufficiently secured, can lead to unexpected and ethically problematical results. Moreover, recent political and regulatory changes make it even easier for providers to access, combine and process behavioural data. In some jurisdictions, they can then sell it on. As business focuses on the bottom line, ethics and privacy have become the victims of the new wave of digital technology". — Tavakkol, Aidin. "Who Owns Your Digital Footprints?" Thestar.com, 27 Mar. 2018, www.thestar.com/opinion/contributors/2018/03/27/who-owns-your-digital-footprints.html.

${ }^{62}$ Golumbia, David. The Politics of Bitcoin: Software as Right-Wing Extremism. University of Minnesota Press, 2016.

${ }^{63}$ Janichen, Stefan, et al. "Self-Sovereign Identity - Opportunities and Challenges for the Digital Revolution." FZI Forschungszentrum Informatik Am Karlsruher Institut Für Technologie, Karlsruhe., 2017, arxiv.org/pdf/1712.01767.pdf.

${ }^{64}$ Janichen, Stefan, et al. "Self-Sovereign Identity - Opportunities and Challenges for the Digital Revolution." FZI Forschungszentrum Informatik Am Karlsruher Institut Für Technologie, Karlsruhe., 2017, arxiv.org/pdf/1712.01767.pdf.

${ }^{65}$ Swan, Melanie. Blockchain: Blueprint for a New Economy. OReilly Media, Inc., 2015.

66 "A private passport service presents a challenge not just to the passport, but to the concept of national identity and other national governance services, such as marriage... If people want to declare themselves as a world citizen and not just whatever nationality they happened to be born as, this is a good way to express that view." - "Blockchain Used as Decentralised Proof of Existence." Futures Centre, 13 Sept. 2017, thefuturescentre.org/signals-of-change/3172/blockchainused-decentralised-proof-existence. 
5. Cabral, Esperanza (2013). Reproductive Health Law in the Philippines. Journal of the ASEAN Federation of Endocrine Societies, 28(1), 26-29. DOI: 10.15605/jafes.028.01.06.

6. Calder, Kent E. (2017). Singapore: Smart City, Smart State". Brookings, Washington D.C. Available at: https://www.researchgate.net/publication/325703627 Singapore Singapore Smart city smart state By Ke nt E_Calder_Washington_DC_Brookings_Institution_Press_2016_Pp_233_Appendix_Notes_Bibiliography Index.

7. Chan, David (2017). Social Futures of Singapore Society. World Scientific, Singapore. Available at: https://ink.library.smu.edu.sg/soss research/2501/

8. Chng, Grace. (2017). Intelligent Island: The Untold Story of Singapore's Tech Journey”. SITF, Singapore. Available at: https://www.tech.gov.sg/media/technews/tech-tales-of-an-intelligent-island

9. Chua, Beng Huat (2017). Liberalism Disavowed: Communitarianism and State Capitalism in Singapore. Singapore: NUS Press. Availabl at: https://nuspress.nus.edu.sg/products/liberalism-disavowedcommunitarianism-and-state-capitalism-in-singapore

10. Chuen, David Lee Kuo (2015). Handbook of Digital Currency: Bitcoin, Innovation, Financial Instruments, and Big Data. Academic Press. Available at: https://www.elsevier.com/books/handbook-of-digital-currency/leekuo-chuen/978-0-12-802117-0

11. Cockell, Charles. (2016). Dissent, Revolution and Liberty beyond Earth. Springer. Available at: https://www.springer.com/gp/book/9783319293479

12. Collantes, Christianne F. (2018). Reproductive Dilemmas in Metro Manila Faith, Intimacies and Globalization, Vol. $1 . \quad$ Singapore: Springer Singapore. Available at: https://www.palgrave.com/gp/book/9789811053900

13. Ecks, Stefan (2004). Bodily sovereignty as political sovereignty: 'self-care' in Kolkata, India, Anthropology \& Medicine, 11(1), 75-89. DOI: 10.1080/1364847042000204906

14. Elliott, Anthony . Routledge Handbook of Identity Studies. Routledge, 2017. Available at: https://www.routledge.com/Routledge-Handbook-of-Identity-Studies/Elliott/p/book/9781138019416

15. Foucault, Michel, and François Ewald (2008). Society Must Be Defended: Lectures at the Collége De France, 1975-76. Penguin. Available at: https://pdflibrary.files.wordpress.com/2008/02/foucault_soc_defended.pdf

16. Foucault, Michel, and James D. Faubion (2002). Power. London: Penguin. Available at: https://www.penguin.co.uk/books/230/23075/power/9780241435083.html

17. Golumbia, David (2016). The Politics of Bitcoin: Software as Right-Wing Extremism. University of Minnesota Press. Available at: https://www.upress.umn.edu/book-division/books/the-politics-of-bitcoin

18. Hinton, Timothy (2013). Equality, Self-Ownership, and Individual Sovereignty. The Philosophical Forum, 44(2), 165-178. Available at: doi:10.1111/phil.12009

19. Huckle, S., \& White, M. (2016). Socialism and the blockchain. Future Internet, 8(4), 49. Available at: doi: HTTP://DX.DOI.ORG.LIBPROXY1.NUS.EDU.SG/10.3390/FI8040049

20. Hodgson, Justin (2019). Post-Digital Rhetoric and the New Aesthetic (Rhetoric and Materiality). Ohio University Press. Available at: https://networks.h-net.org/node/3739868/pdf

21. Janichen, Stefan, et al. (2017). Self-Sovereign Identity - Opportunities and Challenges for the Digital Revolution. Available at: FZI Forschungszentrum Informatik Am Karlsruher Institut Für Technologie, Karlsruhe; arxiv.org/pdf/1712.01767.pdf.

22. Latour, Bruno (1993). We Have Never Been Modern. Harvard University Press. Available at: https://www.hup.harvard.edu/catalog.php?isbn=9780674948396

23. Natarajan, Harish; Krause, Solvej; Gradstein, Helen (2017). Distributed Ledger Technology and Blockchain. FinTech Note; No. 1. World Bank, Washington, DC. World Bank. Available at: https://openknowledge.worldbank.org/handle/10986/29053

24. Manski, Sarah (2017). Building the Blockchain World: Technological Commonwealth or Just More of the Same? Strategic Change, 26(5), 511-522. DOI: $10.1002 /$ jsc. 2151.

25. Ong, Aihwa (2016). Fungible Life: Experiment in the Asian City of Life. Duke University Press. Available at: https://www.dukeupress.edu/fungible-life

26. Pemberton, John (1994). On the Subject of Java. Cornell University Press. Available at: https://academic.oup.com/ahr/article-abstract/101/2/543/157637?redirectedFrom=fulltext

27. Rao, Radhika (2016). Informed consent, body property, and self-sovereignty. Journal of Law, Medicine \& Ethics, $\quad$ Fall, $437 . \quad$ Available

http://ink.galgroup.com/apps/doc/A466051977/LT?u=nuslib\&sid=LT\&xid=a2909bca

28. Swan, Melanie (2015). Blockchain: Blueprint for a New Economy. O'Reilly Media, Inc. Available at: http://shop.oreilly.com/product/0636920037040.do 
29. Trotter, Griffith (2014). Autonomy as Self-Sovereignty. HEC Forum, 26, 237. Available at: https://doiorg.libproxy1.nus.edu.sg/10.1007/s10730-014-9248-2

30. Vaidhyanathan, Siva (2011). The Googlization of Everything: (And Why We Should Worry)". University of California Press. Available at: https://www.ucpress.edu/book/9780520272897/the-googlization-of-everything

\section{Appendix A. Price chart for bitcoin}

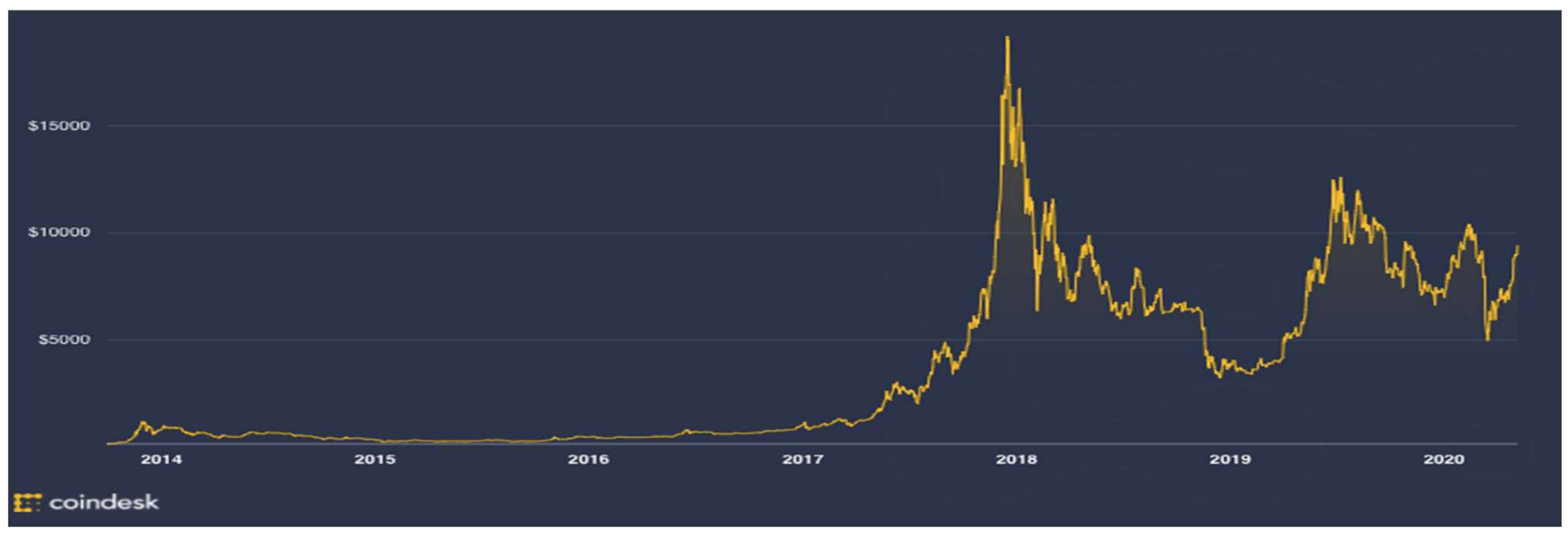

Figure 1. Price chart for bitcoin

Source: May 2020, https://www.coindesk.com/price/bitcoin.

\section{Appendix B. Google Explore data for bitcoin}

Google "Explore" data for the word "bitcoin" (all time, worldwide): Numbers represent search interest relative to the given region and time. A value of 100 shows the country with the most searches for the word 'bitcoin' on Google. A value of 50 means that the term is half as popular.
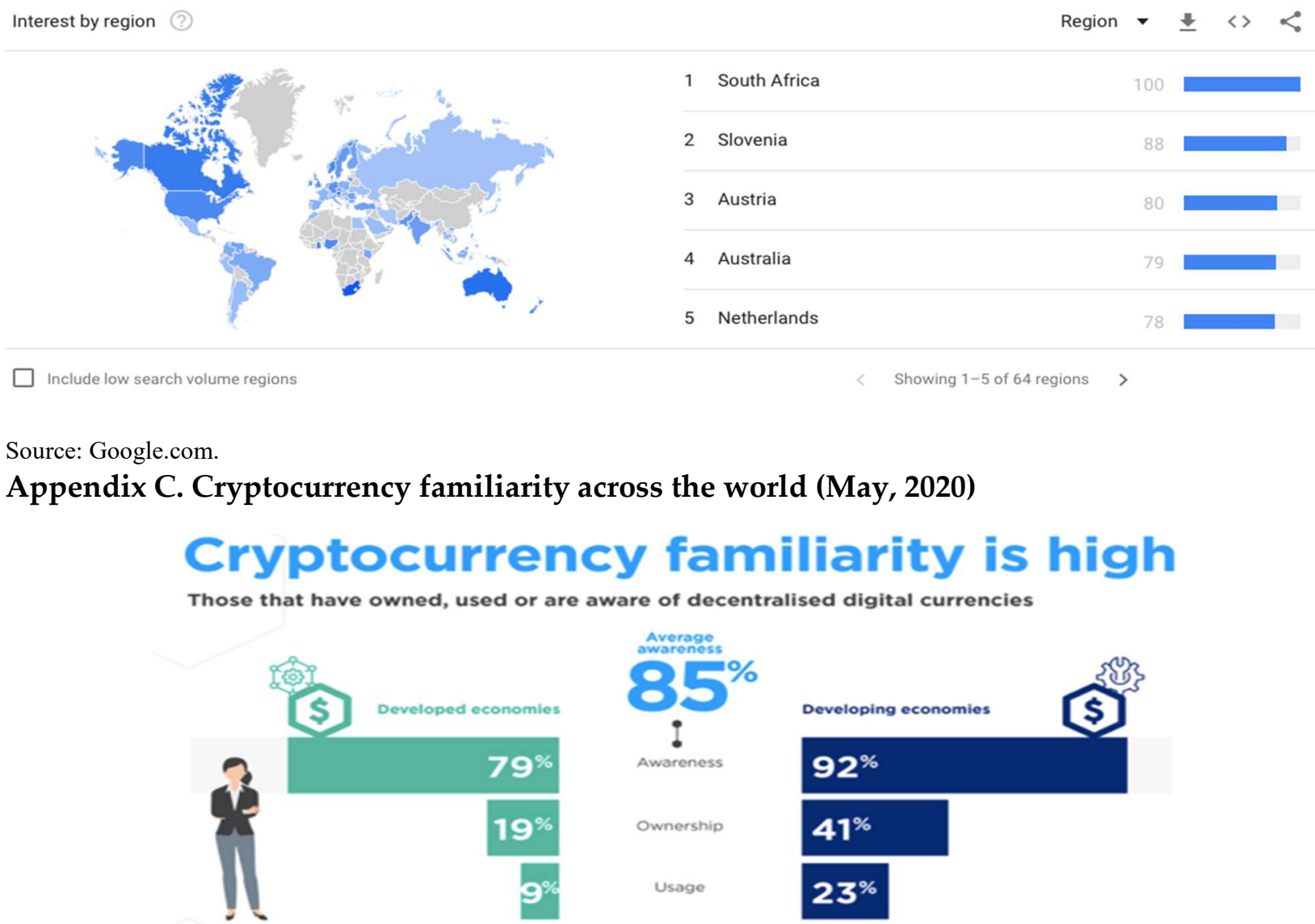
ISSN (online) - 2521-1242 ISSN (print) - 2521-1250

\section{Appendix D. Dog Cartoon 1.}

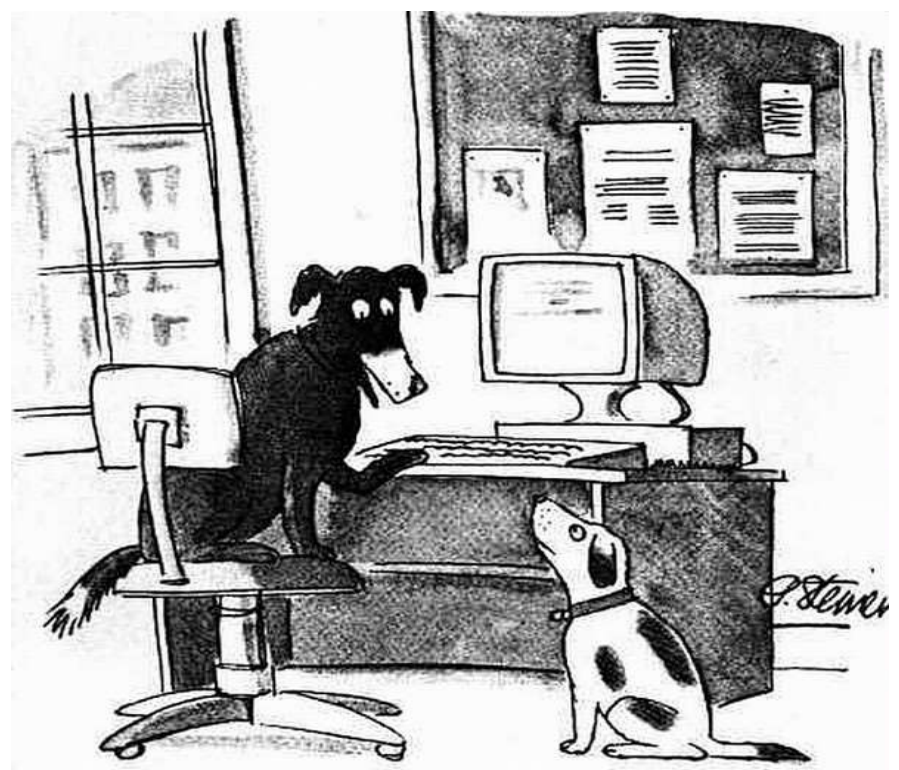

"On the Internet, nobody knows you're a dog."

Source: Peter Steiner, New Yorker Magazine, July 1993.

\section{Appendix E. Dog Cartoon 2.}

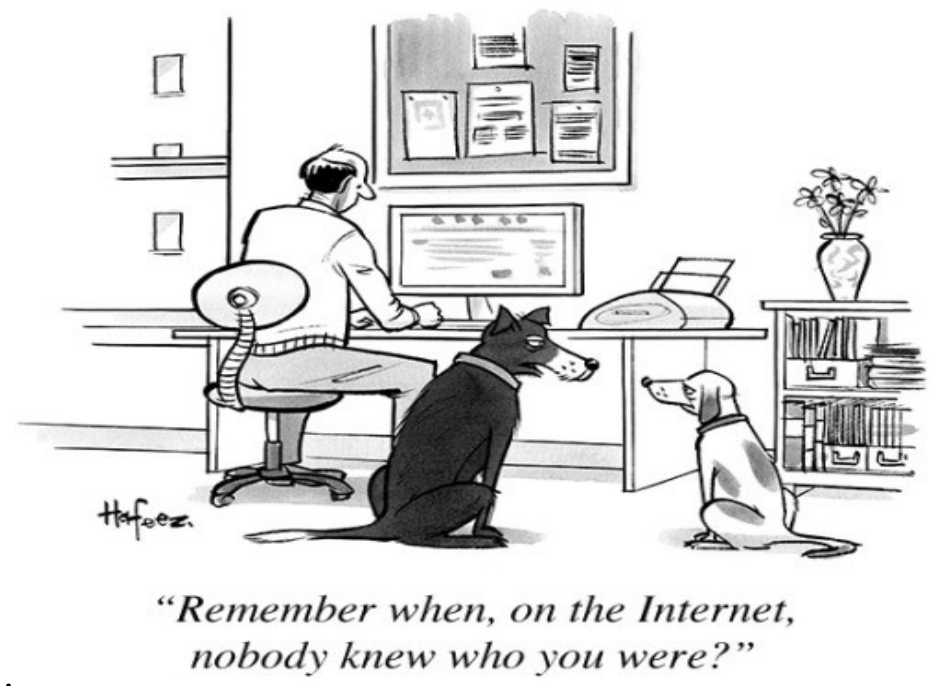

Source: Kaamran Hafeez, The New Yorker Magazine, April 2015. 
Appendix $\mathbf{f}^{67}$

\section{Can Facebook develop a conscience?}

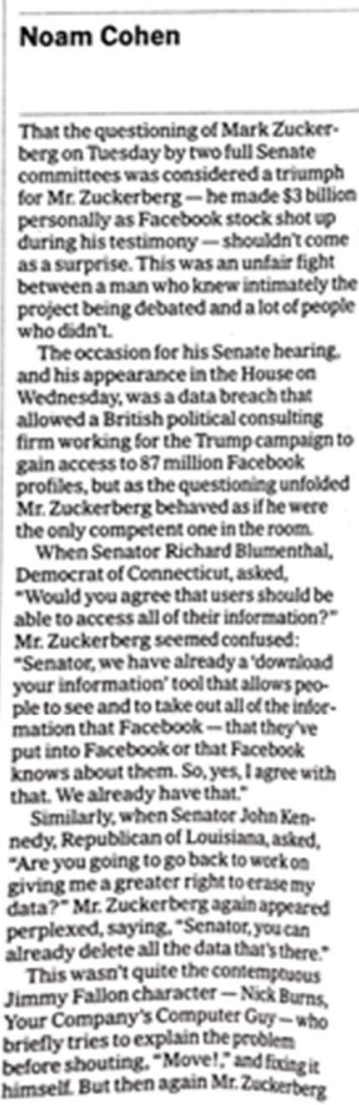

had the benefit of intensive politeness training

Mr. Zuckerberg has been winning these unfair fights going on 15 years now. The idea that he's the Computer Guy and we are the helpless dice work. Facebook and Silicon Valley more broadly.

Famously, Facebook itself is the residue of an early unfair fight. Back in 2003, Mr. Zuckerberg was hired by three 2003 , Mr. Zuckerberg was hired by thr and Ther Winklevoss and their friend Diry Divya Narendra - to write code foe Zuckerberg soondropont the task toreappear a couple of months tarer Feb 4,2004 , with a social network site called Thefarebookcom

The allegation that Mr Zuckerber stole the idea was fought in court and ended in a serticment that petted and Winklevosses and Mr. Narendacash and compuny stock worth tens of mit. lions of dollars. Mr. Zuckerterg plowed ahead under a new paradigm, late: defined by Matt Welsh, Mr. Zucker. berg's computer science prodessor at Harvard, as "Nerds win-

ideas are cheap and don't mean squat if you don't know how to execute on them," Mr. Welsh explained in 2010 on his blog in response to the nasty portrait of Mr. Zuckerberg in the movie The Social Network": "To have an impact you need both the vision and the echnical chops, as well as the tenacity o make something real. Mark was able o do all of those things, and I think he deserves every bit of success that omes his way."

In the past, Mr. Zuckerberg's talents could only be a tool for richer and betterconnected peers like the Winklevosses, who would provide the money and define the purpose of the project. By the mid-2000s, however, Mr. Zuckerberg could turn the tables.

\section{The fact that we could sort of rent machines foc, you know, like $\$ 100$ a month and use that to scale up to a point where we had 300,000 users is pretty cool and it's a pretty unique thing thats going on in techrology nght now, Mr. science students when he came bask to campus in 2005 as a 21 -year-ald entre- preneur. \\ At the time of the talk, Mr. Zuckerberg estimated that Google had 250 million} page views a day, with thousands of machines and 5,000 employees, while Facebook had significantly more page views (400 million), If his chines and just barely congressional $50 \mathrm{cmployees}$. testimony is By then, Larry any guide, Page and Sergey Brin Mark had already given up Zuckerberg control of Google as wont be the price for venture capital to keep the meject running. makes it agreeing to an out.
happen. as investors had insisted. To this day,

Mr. Zuckerberg retains majority contro over Facebook and remains its chiet executive - his decisions about reg tion, privacy and transparency can mean hapoiness or misery for the more than two billion citizens of Facebook nation - majestic powers that are enshrined when you check the right boox on the terms of service agreement. Peter Thiel, the first outside investor in Facebook and a longtime adviser to Mr. Zuckerberg, sees a founder-led tech start-up as something loe an independent cell that can help drive social change. "A start-up," he writes in his book, Zero to One," "is the largest endeavor over which you can have Oefinite mastery. You can have agency not just over your own life, but ovency

\begin{abstract}
small and important part of the world In these extraordinary times, we are Karning bow society changes when it is in the hands of power-drunkengireers. Products and services are defivently we much more reliably and efricienty. We are able to communscate quickerions rectly, widely. But there are far more problems, too, and they are talized at serious than eve first. Tostart, these Silicon Valley titans ar in denial about history. They pride themselves on not bending to what has come before. Is there racism't happen on in the United Seates? my watchi Computed by the few senators coloc. When pressebook's complicity in of color about Facebook simed exclu. running real estate ads which would sively at white people, Which wo violate the Fair Hod this as a partic Zuckerberg detined this as a particularly compeling challeng

intelligence software. Ads can no jonger be explicitly tar. geted to racial groups, be said, thougn, of course, the rub is that there are plenty of surrogates for race that advertisers can presumably still use. This led to the absurd observation from Mr. Zuckerberg, in response to a question from Senator Mazie Hirono, Democrat of Hawail, that "most of the enforcement today is still that our community flags issues for us when that comes up." How the community can identify when a rea estate ad is appearing only to white people remains a mystery.

Despite the length of $\mathrm{Mr}$. Zucker. berg's Senate appearance, there was no serious reckoning with what happened in the 2016 election. Instead, there was an insistent focus on the future, which for Mr. Zuckerberg was synonymous with one phrase, , was synonymous wears, he promised, artificial to 10 years, he promised, artificial intelly. COHEN, PAGE IS
\end{abstract}

\section{STAGES OF DATA PRIVAGY GRIEF}

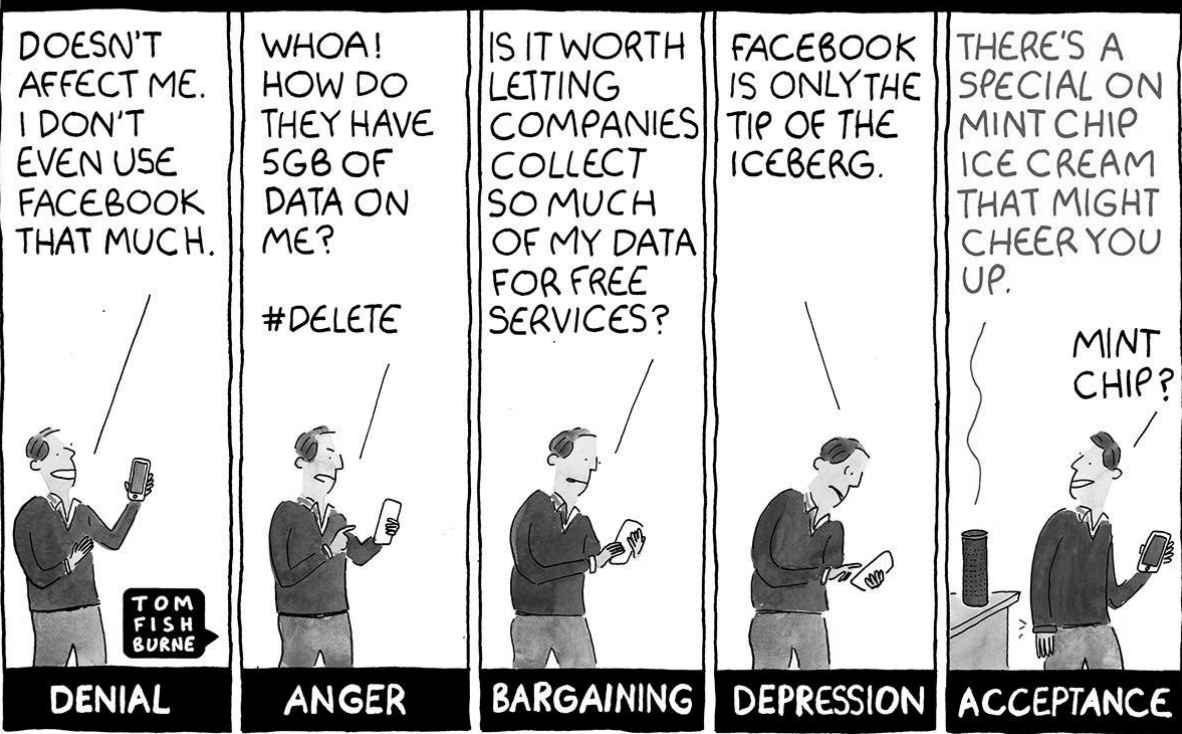

${ }^{67}$ Cohen, Noam. "Can Facebook Develop a Conscience?” The New York Times, The New York Times, 11 Apr. 2018,

www.nytimes.com/2018/04/11/opinion/facebook-zuckerberg-testimony-conscience.html. 